\section{SOI: $\underline{1.1 / \mathrm{TAS}}$ DOI: $\underline{10.15863 / \mathrm{TAS}}$ International Scientific Journal Theoretical \& Applied Science}

\author{
p-ISSN: 2308-4944 (print) e-ISSN: 2409-0085 (online) \\ Year: $2015 \quad$ Issue: 03 Volume: 23 \\ Published: $30.03 .2015 \quad \underline{\text { htp://T-Science.org }}$
}

Igor Viktorovich Balynin postgraduate student Financial University under the Government of the Russian Federation, Russia igorbalynin@mail.ru

SECTION 22. Policy. Innovations. Theory, practice and methods.

\title{
POLITICAL CULTURE OF YOUNGER GENERATION OF RUSSIANS: SURVEY RESULTS 2014
}

Abstract: The article presents the results of the survey of the Russian youth in November 2014 to 14 issues, conducted on the basis of a questionnaire designed to determine the political culture by typology G.Almond and S.Verba. Given the legal regulation of the electoral process in the Russian Federation, as well as domestic and international experience in the field of activation of young people to participate in elections.

Key words: Politics, elections, youth, political socialization, political culture, electoral activity, voting rights.

Language: Russian

Citation: Balynin IV (2015) POLITICAL CULTURE OF YOUNGER GENERATION OF RUSSIANS: SURVEY RESULTS 2014. ISJ Theoretical \& Applied Science 03 (23): 25-32.

Soi: http://s-o-i.org/1.1/TAS*03(23)5 Doi: crossef http://dx.doi.org/10.15863/TAS.2015.03.23.5

\section{ПОЛИТИЧЕСКАЯ КУЛЬТУРА МОЛОДОГО ПОКОЛЕНИЯ РОССИЯН: ИТОГИ ОПРОСА 2014 ГОДА}

Аннотация: В статье представлены результаты анкетирования российской молодежи в ноябре 2014 года по 14 вопросам, проведенного на основе разработанного опросника с целью определения политической культуры по типологии Г.Алмонда и С.Верба. Приведены нормативно-правовое регулирование избирательного процесса в Российской Федерации, а также отечественный и международный опыт в сфере активизации молодежи к участию в выборах.

Ключевые слова: политика, выборы, молодежь, политическая сочиализачия, политическая культура, электоральная активность, избирательные права.

«Выборы - это индикатор гражданской позиции молодежи, ее отношения к демократии и народовластию, к будущему страны, выражение доверия к российской избирательной системе» такое определение приводится в одной из статей на сайте Центральной избирательной комиссии.

Действительно, роль молодежи является весомой в любом избирательном процессе. Очень важно, чтобы молодые люди обладали высокой политической и правовой культурой, активно выражали свою гражданскую позицию. Повышение политической и правовой культуры молодых граждан, а также увеличение их электоральной активности - одна из главных задач современного государства.

В настоящее нормативно-правовое регулирование избирательного процесса в Российской Федерации является достаточно объемным, которое включает Конституцию Российской Федерации, федеральные конституционные законы, федеральные законы, Указы Президента и Постановления Правительства, региональные законы, нормативно-правовые акты избирательных комиссий и органов местного самоуправления.

Так, пунктом 3 статьи 3 Конституции Российской Федерации определено, что «высшим непосредственным выражением власти народа являются референдум и свободные выборы». Более того, пунктом 1 статьи 32 гарантируется право граждан Российской Федерации «в управлении делами государства как непосредственно, так и через своих представителей», а пунктом 2 - «право избирать и быть избранными в органы государственной 
власти и органы местного самоуправления, а также участвовать в референдуме» [1].

Статья 11 Конституции Российской Федерации посвящена государственной власти на федеральном и региональном уровнях, а статья 12 - местному самоуправлению.

Более того, в статье 81 Конституции Российской Федерации указаны такие важнейшие принципы избирательного права как всеобщнсть, равенство и тайна голосования. Отметим, что они приведены в отношении выборов Президента Российской Федерации. Детальнее избирательный процесс рассмотрен в соответствующих федеральных законах.

Согласно ст. 15 Конституции Российской Федерации «общепризнанные принципы и нормы международного права и международные договоры Российской Федерации являются составной частью ее правовой системы» [1]. Так, в соответствии со статьей 21 Всеобщей декларации прав человека «воля народа должна быть основой власти правительства; эта воля должна находить себе выражение в периодических и нефальсифицированных выборах, которые должны проводиться при всеобщем и равном избирательном праве путем тайного голосования или же посредством других равнозначных форм, обеспечивающих свободу голосования» [2].

Кроме этого, в соответствии с пунктом b статьи 25 Международного пакта о гражданских и политических правах «каждый гражданин должен иметь без какой бы то ни было дискриминации и без необоснованных ограничений право и возможность голосовать и быть избранным на подлинных периодических выборах, производимых на основе всеобщего равного избирательного права при тайном голосовании и обеспечивающих свободное волеизъявление избирателей» [3].

Основные гарантии реализации гражданами Российской Федерации конституционного права на участие в выборах и референдумах, проводимых на территории Российской Федерации в соответствии с Конституцией Российской Федерации, федеральными законами, конституциями (уставами), законами субъектов Российской Федерации, уставами муниципальных образований установлены соответствующим федеральным законом [4], состоящим из 11 глав.

Глава 1 «Общие положения» включает статьи 1-11.1. Так, статьей 1 указанного выше закона обозначены пределы его действия, в статье 2 представлены ключевые понятия и термины. Статьей 3 определены принципы организации и проведения выборов и референдумов на территории Российской Федерации. В последующих статьях детально рассмотрены понятия всеобщего, равного и прямого избирательного права и права на участие в референдуме, а также тайна голосования, срок полномочий органов государственной власти и местного самоуправления и др.

В глава 2,3,5,7 и 9 приведены гарантии права граждан Российской Федерации соответственно на назначение референдума; при регистрации (учете) избирателей, участников референдума, составлении списков избирателей, участников референдума, образовании избирательных округов, избирательных участков, участков референдума; при выдвижении и регистрации кандидатов, реализации инициативы проведения референдума; на получение и распространение информации о выборах и референдумах; при организации и осуществлении голосования, установлении итогов голосования, определении результатов выборов, референдума и их опубликовании.

Главой 6 определен статус кандидатов, инициативной группы по проведению референдума. Четвертая глава посвящена избирательным комиссиям, комиссиям референдума. Главой 8 определен порядок финансирования выборов и референдума. Глава 10 регламентирует порядок обжалования нарушений избирательных прав и права на участие в референдуме граждан Российской Федерации и указана ответственность за нарушение законодательства о выборах и референдумах.

Порядок организации и проведения выборов Президента Российской Федерации и выборов депутатов Государственной Думы Федерального Собрания Российской Федерации подробно рассмотрен в соответствующих федеральных законах.

Важное место в системе нормативноправового регулирования избирательного процесса в Российской Федерации занимают Федеральные законы «Об общих принципах организации местного самоуправления в Российской Федерации» и «Об обеспечении конституционных прав граждан Российской Федерации избирать и быть избранными в органы местного самоуправления». Так, статья 23 Федерального закона «Об общих принципах организации местного самоуправления в Российской Федерации» посвящена назначению и порядку проведения муниципальных выборов. Следует также отметить статью 26 этого закона, которая позволяет гражданам выступать с правотворческой инициативой. 
Таким образом, в настоящее время нормативно-правовое регулирование избирательного процесса в Российской Федерации является достаточно объемным и включает не только нормы российского, но и международного права, создавая все условия россиянам принимать активное участие в выборах с 18 лет.

Проблемы политической культуры и правового воспитания молодого поколения, а также повышения их избирательной активности, являются одной из основных в большинстве стран мира. В этой связи следует подчеркнуть, что подобные вопросы ни один раз обсуждалась как на национальном уровне, так и в мировом сообществе. Так, например, в сентябре 2012 года заместитель секретаря Совета Европы Габриэла Баттани-Драгони заявила следующее:

«Сегодня существуют три крайне серьезных проблемы, которые вызывают особое беспокойство в Европе. Во-первых, мы видим плачевную ситуацию по всей Европе с точки зрения участия молодых людей в жизни общества» [17].

Наиболее сильный интерес молодежи к происходящим в стране политическим процессам среди европейских стран наблюдается в Германии. Главным образом на это оказывает влияние образование как самой молодёжи, так и родителей. Интересно, что в Германии на выборы ходит более 80 процентов молодого поколения страны. В стране существует общественная организация U18, одной из целей которой является повышение электоральной активности немецких подростков. Данная общественная организация независима, создана в 1996 году в Берлине под патронатом комиссии по делам детей и молодежи бундесрата. Как сообщает центр социально-трудовой ориентации и адаптации, U18 проводило специальные выборы в бундестаг, в которых могли принять участие лишь те, кому нет 18 лет. Процедура голосования ничем не отличается от той, которая проводится обычно. Результаты голосования в дальнейшем были размещены в сети интернет. Целью этого голосования было приобщение молодёжи с подросткового возраста к участию в выборах будущего Германии [18].

Однако, не только в Германии, но и в других европейских государствах отмечается высокая явка среди молодёжи. Так, например, во Франции большая часть молодого поколения приняла участие в президентских выборах 2012 года. Среди причин эксперты называют наличие заинтересованности, вызванной выступлениями французских политиков [20].
Значительную роль в повышении уровня электоральной активности молодёжи играет Центральная избирательная комиссия и избирательные комиссии субъектов Российской Федерации, которые проводят масштабную кампанию по повышению политической культуры современного молодого поколения. Одним из главных шагов этой плодотворной работы, является принятие решения о проведении в субъектах Российской Федерации «Дня молодого избирателя» каждое третье воскресенье февраля. Данное решение было принято Постановлением Центральной избирательной комиссии Российской Федерации от 28 декабря 2007 г. № 83/666-5 «О проведении Дня молодого избирателя».

Постоянно идет работа по повышению политической и правовой культуры молодёжи в регионах. В этом контексте хотелось бы привести опыт Калужской области. Так, в 2011 году была проведена целая неделя молодого избирателя в период с 14 по 27 февраля 2011года под девизом «Живи настоящим - думай о будущем!», что безусловно, является положительным опытом для заимствования другими российскими регионами. Так по инициативе избирательной комиссии Калужской области 19 июня 2012 года в Муниципальном образовании «Износковский район» прошел круглый стол «Актуальные проблемы (позитивные аспекты) повышения правовой культуры избирателей Калужской области». Один из ключевых вопросов круглого стола - повышение правовой культуры молодых калужан. В работе мероприятия активное участие приняла сотрудник аппарата Уполномоченного по правам человека Елена Коржуева. В настоящее время на территории области проводится областной турнир по парламентским дебатам «Лавка», где молодые люди могут подискутировать на самые волнующие вопросы и затронуть самые актуальные темы.

Огромную роль в повышении электоральной активности населения (в т.ч. и молодого) играет Аппарат Уполномоченного по правам человека в Российской Федерации. Так, например, в сентябре 2014 года он проводил мониторинг соблюдения прав граждан Российской Федерации в единый день голосования [19], в результате которого был собран значительный материал, который позволит в дальнейшем решить имеющиеся проблемы в этой сфере.

Колоссальную работу выполняют омбудсмены на региональном уровне. Так, например, Аппарат Уполномоченного по правам человека в Калужской области в 2013 году отметил 10-летие своего существования. Следует отметить его активную и плодотворную работу в 
рамках защиты прав и свобод гражданина. При этом, хотелось бы подчеркнуть особую роль в повышении электоральной активности молодёжи. В этом направлении сделано достаточно много. Так, в частности постоянно организуются, уже ставшие традиционными, встречи Уполномоченного со студентами вузов и ссузов области, школьниками, журналистами. Более того, осуществляются личные приемы Уполномоченного в районах области, а также выезды юристов для оказания бесплатной юридической помощи. Это повышает возможности граждан (в том числе и молодых) по квалифицированной защите своих прав. В свою очередь, граждане, имеющие подобные механизмы защиты своих прав, становятся более внимательны к происходящим в стране и регионе политическим процессам, что безусловно ведет к увеличению электоральной активности.

Одним из проектов, в составе организаторов которых выступил Уполномоченный по правам человека - областной фестиваль социальной рекламы «ВКЛючайся!», который проходил с ноября 2012 по март 2013 годов. Кроме того, в 2012 году Уполномоченный по правам человека принял участие в работе форума «Высокие берега». Следует отметить, что участие носило не только информационно-консультативный характер, но и практический. Так, в частности, был проведен тренинг «Умение работать в коллективе».

Повышению политической и правовой культуры калужской молодёжи способствует ежегодный конкурс научных работ «Права человека и будущее России», позволяющий студентам высказать свою позицию по актуальным проблемам.

Важную роль в повышении политической и правовой культуры играют молодёжные организации, волонтёрские и другие общественные объединения и движения, а также учебные заведения. Так, например, сочинские студенты смогли принять участие в конкурсе видеороликов «Да! К выбору». В свою очередь, в саратовских вузах проводился конкурс «Твои FOTОвыборы», где все желающие смогли представить на суд зрителей фотографий по нескольким номинациям. Активисты общественных организаций и волонтёрских движений Биробиджана устроили флеш-моб, посвященный президентским выборам. Девизами проводимой акции стали лозунги: «Будь отважен - твой голос важен!» и «Голосуй - не комплексуй!».

Активной оказалась и владимирская молодёжь, по инициативе которой были проведены политические дебаты. Тема дебатов была выбрана инициаторами самостоятельно «Быть политиком, быть гражданином». Во время проведения дебатов молодёжь смогла не только обсудить выдвинутые партиями предложения, но и представить свои собственные. По окончании дебатов активисты говорили о необходимости проведения подобных мероприятий в перспективе, отмечали, что постоянство подобных встреч - это шаг к успеху в решении проблемы привлечения молодёжи к существующим политическим и правовым проблемам.

Следует отметить огромную роль Молодежного союза экономистов и финансистов в повышении активности (в т.ч. и электоральной) молодого поколения Российской Федерации. Прежде всего, это связано с ежегодным проведением большого количества олимпиад и конкурсов, которые позволяют российской молодежи реализовать свои способности и раскрывать научный, творческий и духовный потенциалы.

Успешную работу в правовом воспитании молодежи проводит информационно-справочная система «Консультант», которая предоставляет возможность всем студентам изучать законодательство, как федеральное, так и региональное, как действующее, так и уже отмененное. Помимо предоставления доступа к нему, специалисты этой системы в регионах проводят постоянные встречи со студентами большинства вузов нашей страны, где рассказывают не только о том, как пользоваться их системой, но и о новейших изменениях законодательства в профильных для этих студентов отраслях права. Формой преподнесения является игровая с последующим вручением памятных призов и подарков. Кроме этого, на официальном сайте системы постоянно проводятся онлайн-игры по правовым вопросам, что позволяет молодым людям в достаточно увлекательной и интересной форме познавать нормы права различных отраслей.

Положительным является и опыт компании «Гарант», которая тоже позволяет молодым россиянам работать как с действующими, так и отменёнными нормативно-правовыми актами. Более того, все желающие могут посмотреть выпуски «Правовое обозрение», а также подписаться на обзоры последних изменений законодательства, которые будут высылаться на адрес электронной почты, тем самым, предоставляя возможность всегда оставаться в рамках действующих норм права. Компания ежегодно проводит конкурс «Правовая Россия», одной из номинаций которого является «Правовая надежда России». 
Одним из перспективных направлений в работе над повышением правовой культуры населения является создание так называемых юридических клиник при высших учебных заведениях. Так, 27 мая в рамках IV областной научно-практической конференции преподавателей вузов «Вопросы правового просвещения учащихся ВУЗов», а затем в октябре 2013 года Калужский обмудсмен верно отметил, что деятельность подобных структур не только позволяет накапливать опыт будущим юристам, но и дает возможность получить достоверную правовую информацию малообеспеченным гражданам.

В начале 60-х годов двадцатого столетия Габриель Алмонд совместно с Сиднеем Верба опубликовали ставшую впоследствии широко известной монографию «Гражданская культура» [5]. Она была написана на основе материалов, полученных в результате сравнения результатов исследования политических культур США, Великобритании, Германии, Италии и Мексики. Данное исследование подразумевало анализ политической ориентации индивида (включающей три компонента - когнитивный, аффективный и оценочный) на четыре основных объекта: политическую систему в целом, правительство, общенациональные выборы, саму личность. При этом, учеными было выделено три идеальных типа политической культуры: патриархальный, подданнический и культуры участия.

На основе этой, уже ставшей классической, модели, нами был составлен опросник, который включал в себя 14 вопросов В анкетировании приняли участие - 200 человек (100 студентов Калужского филиала Финансового университета при Правительстве Российской Федерации и 100 студентов Калужского филиала Российской академии народного хозяйства и государственной службы при Президенте Российской Федерации). Опрос проводился в ноябре 2014 года. Результаты обработки данных, полученных по итогам анкетирования, представлены в таблице 1.

Проанализируем результаты, полученные по каждому вопросу:
1. Как высоко Вы оцениваете свои знания о политической системе и ее истории?

Большинство участников опроса оценили свои знания о политической системе и ее истории на среднем уровне $(71,4 \%), 15,7 \%$ респондентов - «низко», лишь $6 \%$ посчитали свои знания высокими.

2. Каково Ваше отношение к службе в армии?

Положительное отношение к службе в армии отмечается у 78,1 \% участников опроса, отрицательное - у 21,9\%.

3. Как Вы можете оценить современную политическую систему Российской Федерации?

Положительную оценку дали 36,9 \% респондентов, отрицательную - 11,5 \%, и 51,6 \% дали сдержанную оценку.

4. Знакомы ли Вы со структурой и ролью политической элиты Российской Федерации?

Ответы на данный вопрос разделились следующим образом - 65,90 \% опрошенных ответили, что знакомы, и $34,10 \%$ - что не знакомы

5. Какие предложения и инициативы политических партий РФ Вам известны?

К сожалению, только 36,5 \% респондентов смогли ответить на этот вопрос. Примечательно, что наиболее известными инициативами оказались увеличение материнского капитала, заработной платы, пособий, пенсий, стипендий, а также создание уставных судов в субъектах Российской Федерации, сокращение рабочей недели, запрещение показа западных фильмов и предложение В.В. Жириновского о необходимости сделать Россию империей.

6. Как Вы можете выразить свои чувства относительно предложений и инициатив политических партий, указанных в предыдущем пункте?

Важно отметить, что 96,90\% респондентов (из числа ответивших на предыдущий вопрос) смогли выразить свои чувства относительно названных инициатив и предложений путем согласия или несогласия с ними и приведением аргументации своей позиции.

Таблица 1

Результаты анкетирования российской молодежи в ноябре 2014 года

\begin{tabular}{|c|l|c|}
\hline № п/п & \multicolumn{1}{|c|}{ Показатель } & 3начение \\
\hline 1 & \multicolumn{1}{|c|}{2} & 3 \\
\hline 1 & \multicolumn{1}{|c|}{ Забракованные анкеты, \% } & 11,00 \\
\hline 2 & $\begin{array}{l}\text { Вопрос 1. Как высоко Вы оцениваете свои знания о политической системе и ее } \\
\text { истории? (низкий; средний; высокий; очень низкий; очень высокий уровни), } \\
\text { \% }\end{array}$ & $\begin{array}{c}15,73 ; 71,35 ; 6,74 ; \\
1,69 ; 4,49\end{array}$ \\
\hline 3 & $\begin{array}{l}\text { Вопрос 2. Каково Ваше отношение к службе в армии? } \\
\text { (положительное; отрицательное; затруднились с ответом), \% }\end{array}$ & 78,$09 ; 21,91 ; 0,00$ \\
\hline
\end{tabular}




\begin{tabular}{|c|c|c|}
\hline № п/п & Показатель & Значение \\
\hline 4 & $\begin{array}{l}\text { Вопрос 3. Как Вы можете оценить современную политическую систему? } \\
\text { (положительная; отрицательная; сдержанная оценки), \% }\end{array}$ & 36,$9 ; 11,5 ; 51,6$ \\
\hline 5 & $\begin{array}{l}\text { Вопрос 4. Знакомы ли Вы со структурой и ролью политической элиты РФ? } \\
\text { (знакомы; не знакомы) }\end{array}$ & 65,$9 ; 34,1$ \\
\hline 6 & $\begin{array}{l}\text { Вопрос 5. Какие предложения и инициативы политических партий РФ Вам } \\
\text { известны? (процент ответивших на этот вопрос) }\end{array}$ & 36,5 \\
\hline 7 & $\begin{array}{l}\text { Вопрос 6. Как Вы можете выразить свои чувства относительно предложений и } \\
\text { инициатив политических партий, указанных в предыдущем пункте? (процент } \\
\text { ответивших на этот вопрос из числа давших ответ на пятый вопрос) }\end{array}$ & 96,90 \\
\hline 8 & $\begin{array}{l}\text { Вопрос 7. Приведите, пожалуйста, одно из последних и } \\
\text { запомнившихся Вам высказываний } \\
\text { (процент ответивших на этот вопрос) }\end{array}$ & 43,82 \\
\hline 9 & $\begin{array}{l}\text { Вопрос 8. Согласны ли Вы с этим высказыванием? Как Вы можете оценить } \\
\text { его? (процент ответивших на этот вопрос из числа давших ответ на седьмой } \\
\text { вопрос) }\end{array}$ & 98,72 \\
\hline 10 & $\begin{array}{l}\text { Вопрос 9. Если бы Вы занимали высокопоставленную должность, стали бы } \\
\text { Вы трудоустраивать своих родственников на наиболее почетные и } \\
\text { высокопоставленные посты? (да; нет; возможно) }\end{array}$ & 52,$2 ; 45,3 ; 2,5$ \\
\hline 11 & $\begin{array}{l}\text { Вопрос 10. Ожидаете ли Вы от государства получения определенных благ? } \\
\text { (да; нет) }\end{array}$ & 73,$2 ; 26,8$ \\
\hline 12 & $\begin{array}{l}\text { Вопрос 11. Считаете ли Вы себя полноценным участником политических } \\
\text { отношений? (да; нет) }\end{array}$ & 30,$6 ; 69,4$ \\
\hline 13 & $\begin{array}{l}\text { Вопрос 12. Знаете ли Вы свои политические права и обязанности? (знают; не } \\
\text { знают) }\end{array}$ & 93,$0 ; 7,0$ \\
\hline 14 & $\begin{array}{l}\text { Вопрос 13. Обладаете ли Вы стремлением активно воздействовать на } \\
\text { политику? (обладают; не обладают) }\end{array}$ & 27,$8 ; 72,2$ \\
\hline 15 & $\begin{array}{l}\text { Вопрос 14. Обсуждаете ли Вы вопросы политики в кругу друзей? (да; нет; } \\
\text { иногда) }\end{array}$ & 54,$7 ; 28,2 ; 17,1$ \\
\hline
\end{tabular}

Источник: составлено и рассчитано автором на основании обработки результатов опроса

7. Приведите, пожалуйста, одно из последних и наиболее запомнившихся Вам высказываний политического деятеля (деятелей).

На этот вопрос ответило на 7,3\% больше респондентов по сравнению с пятым вопросом $43,8 \%$. Чаще других респонденты вспоминали высказывания Президента Российской Федерации В.В. Путина $(32,50 \%$ опрошенных) и лидера Либерально-демократической партии России В.В. Жириновского (34,60 \% опрошенных). Кроме того, участники опроса вспомнили Председателя Правительства Д.А. Медведева, Министра обороны С.К.Шойгу, лидера Коммунистической партии Российской Федерации Г.А. Зюганова, и даже, В. И. Ленина, В.С. Черномырдина, В.В Кличко и др.
Так, наиболее часто респонденты приводили следующие высказывания:

А) «Медведь ни у кого разрешения спрашивать не будет и тайги своей он никому не отдаст» (В.В.Путин).

Б) «Хватит это терпеть» (В.В.Жириновский).

В) «А сегодня в завтрашний день, не все могут смотреть. Вернее смотреть могут не только лишь все, мало кто может это делать». (В.В.Кличко).

8. Согласны ли Вы с этим высказыванием? Как Вы можете оценить его?

98,72\% ответивших на предыдущий вопрос очень активно высказывали свое мнение, достаточно подробно аргументируя свою позицию. 
9. Если бы Вы занимали высокопоставленную должность, стали бы Вы трудоустраивать своих родственников на наиболее почетные и высокопоставленные посты?

Практически все участники опроса дали свой ответ на этот вопрос, большинство дали развернутый ответ с пояснением своего положительного или отрицательного ответа. Все ответы следует разделить в несколько групп:
I. Да $-52,2 \%$
II. Нет $-45,3 \%$
III. Возможно $-2,5 \%$

10. Ожидаете ли Вы от государства получения определенных благ?

$73,2 \%$ - ожидают

$26,8 \%$ - не ожидают

11. Считаете ли Вы себя полноценным участником политических отношений?

Всего на этот вопрос ответили 95,51 \% респондентов.

$30,6 \%$ ответивших на этот вопрос считают себя полноценными участниками политических отношений, и 69,4 \% не считают.

12. Знаете ли Вы свои политические права и обязанности?

На этот вопрос ответили 96,63 \% опрошенных.

$93,0 \%$ ответили, что знают, $14,5 \%$ ответили, что не знают своих политических прав и обязанностей.

13. Обладаете ли Вы стремлением активно воздействовать на политику?
На вопрос ответили 94,94\% респондентов.

$27,8 \%$ опрошенных ответили, что обладают подобным стремлением, 72,2 \% - что не обладают таковым.

14. Обсуждаете ли Вы вопросы политики в кругу друзей?

На вопрос ответили 95,51\% респондентов.

54,7 \% опрошенных обсуждают настоящую политическую ситуацию в России и за рубежом, $28,2 \%$ - не обсуждают, $17,1 \%$ - иногда обсуждают.

Таким образом, по итогам анализа результатов анкетирования в 2014 году следует сделать вывод о том, что большая часть молодежи оценивает свои знания о политической системе и ее истории на среднем уровне, положительно относится к службе в армии, знают свои политические права, ожидают получения тех или иных благ от государства, обсуждает вопросы политики в кругу друзей. В то же время не могут привести инициативы политических партий, вспомнить высказывания политических деятелей, не обладают стремлением активно воздействовать на политику, а также стали бы трудоустраивать своих родственников на наиболее почетные и высокопоставленные посты. Так, преобладающими в политической культуре молодых россиян остаются подданнический и патриархальный типы. Многие студенты понимают значимость активной политической позиции, но несколько недооценивают присущие ей рациональность и ответственность.

\section{References:}

1. (2014) Konstituciya Rossijskoj Federacii (posl. izm. ot 21.07.2014).

2. (1948) Vseobshchaya deklaraciya prav cheloveka (prinyata rezolyuciej 217 A (III) General'noj Assamblei OON ot 10 dekabrya 1948 goda).

3. (1966) Mezhdunarodnyj pakt o grazhdanskih i politicheskih pravah (prinyat rezolyuciej 2200 A (XXI) General'noj Assamblei ot 16 dekabrya 1966 goda)

4. (2002) Federal'nyj zakon ot 12 iyunya 2002 goda N 67-FZ "Ob osnovnyh garantiyah izbiratel'nyh prav $\mathrm{i}$ prava na uchastie $\mathrm{V}$ referendume grazhdan Rossijskoj Federacii".

5. Almond Gabriel A., Verba Sidney (1963) The Civic Culture: Political Attitudes and Democracy in Five Nations. Princeton, New Jersey: Princeton University Press, -562p.
6. Almond G, Verba S (1992) Grazhdanskaya kul'tura i stabil'nost' demokratii. Polis (Politicheskie issledovaniya), 1992. №4. pp. 122-134.

7. Betekhtina AV, Oluhov NV (2012) EHlektoral'noe povedenie molodezhi: pochemu molodezh' ne hodit na vybory? Voprosy upravleniya. 2012. № 1 (1). pp. 012-020.

8. ZHirkova SK (2014) Problema absenteizma rossijskoj molodezhi (regional'nyj aspekt). Intellektual'nyj potencial XXI veka: stupeni poznaniya. 2014. № 21. pp. 90-92.

9. Kukolev AV (2014) Potencial lokal'nyh social'nyh struktur kak ehlementa upravleniya ehlektoral'noj aktivnost'yu molodyozhi. Molodoj uchenyj. 2014. № 8. pp. 511-513.

10. Ratnikova GA (2013) Poryadok formirovaniya molodezhnyh parlamentskih struktur V 
Rossijskoj Federacii. Problemy prava. 2013. № 1 (39). pp. 49-59.

11. Reznik S, CHernikovskaya M (2010) Organizacionnaya kul'tura studenchestva: sistema i mekhanizmy upravleniya / Problemy teorii i praktiki upravleniya. 2010. № 9. pp. 3542.

12. Sadyrova MY (2014) Problema izbiratel'noj aktivnosti rossijskoj molodezhi. Molodoj uchenyj. 2014. № 3 (62). pp. 667-669.

13. Starceva SG (2012) Vybory kak osnovnaya forma politicheskogo uchastiya molodyozhi. Vlast'. 2012. № 1. pp.49.

14. Tokar' NO (2013) Politicheskaya socializaciya molodyozhi v usloviyah demokratizacii rossijskogo obshchestva. Politika i obshchestvo, 2013, № 8, pp.1034-1038.

15. Carihin VA (2014) EHlektoral'naya aktivnost' molodezhi v sovremennoj Rossii. Nauchnoe obozrenie. Seriya 2: Gumanitarnye nauki. 2014. № 1. pp. 40-44.

16. Carihin VA (2014) EHlektoral'naya aktivnost' molodezhi na primere Respubliki Bashkortostan. Nauchnoe obozrenie. Seriya 2: Gumanitarnye nauki. 2014. № 1. pp. 45-49.
17. (2015) Aktual'nye kommentarii. Evropu bespokoit apatiya molodyozhi. Available: http://actualcomment.ru/news/48864/ (Accessed: 9.03.2015).

18. (2015) V Germanii prohodyat trenirovochnye detskie vybory $\mathrm{v}$ Bundestag. Available: http://www.cstaip.ru/news/newsindex5060.html (Accessed: 9.03.2015).

19. (2015) Upolnomochennyj po pravam cheloveka v Rossijskoj Federacii. Neobhodimo povysit' real'nuyu sostyazatel'nost' izbiratel'nogo processa i vnimatel'nee prislushivat'sya $\mathrm{k}$ mneniyu izbiratelej. Available: http://ombudsmanrf.org/news/novosti upolnom ochennogo/view/neobkhodimo_povyshat_realn uju_sostjazatelnost izbiratelnogo_processa_i_v nimatelnee prislushivatsja $\mathrm{k}$ mneniju izbiratel ej (Accessed: 9.03.2015).

20. (2015) Fenomen francuzskoj yavki: otkuda berutsya $\quad 80 \quad \%$ ? $\quad$ Available: http://www.bbc.co.uk/russian/society/2012/04/1 20424 france high turnout.shtml (Accessed: 9.03.2015). 